\title{
Basidiomycete Genomics
}

\section{de Vries, Ronald}

2018-03

de Vries , R, Mäkelä , M R , Hilden , S K \& Kämper , J 2018 , ' Basidiomycete Genomics ' ,

Fungal Genetics and Biology , vol. 112 , no. 1 , pp. 1-1 . https://doi.org/10.1016/j.fgb.2018.02.002

http://hdl.handle.net/10138/307214

https://doi.org/10.1016/j.fgb.2018.02.002

cc_by_nc_nd

acceptedVersion

Downloaded from Helda, University of Helsinki institutional repository.

This is an electronic reprint of the original article.

This reprint may differ from the original in pagination and typographic detail.

Please cite the original version. 


\section{Basidiomycete Genomics}

Genomes and post-genomic tools have an impact on every field of biology, and this is particularly true for the field of basidiomycete research. While these fungi have a long history of research, several factors have caused a slower progress in understanding specific biological features when compared to the research in ascomycete fungi. One reason for this is that no basidiomycete fungus has a research community as large as for the various 'model' ascomycetes, such as several Aspergillus nidulans, $A$. niger, Aspergillus fumigatus, Aspergillus oryzae, Neurospora crassa, Trichoderma reesei or Penicillium chrysogenum. In addition, genetic modification has been challenging in many basidiomycete fungi, especially in wood decaying white rot and brown rot species.

A significant moment in basidiomycete research was the publication of the Phanerochaete chrysosporium (Martinez, Larrondo et al. 2004) and Ustilago maydis (Kämper, Kahmann et al. 2006) genomes, as this provided a wealth of information on the molecular basis of many biological processes. It also revealed both similarities with and differences to ascomycete fungi, for which several genomes were already available at the time.

During the past 10 years, basidiomycete genomics has developed exponentially. While initially the genomes of individual species were sequenced (e.g. (Eastwood, Floudas et al. 2011) (Morin, Kohler et al. 2012) (Ohm, de Jong et al. 2010)), sequencing has more recently switched to increasingly large sets of species enabling detailed comparative studies (e.g. (Duplessis, Cuomo et al. 2011) (Floudas, Binder et al. 2012) (Binder, Justo et al. 2013) (Kohler, Kuo et al. 2015)), not only at the genomic but also at the transcriptomic and proteomic level. One result of this is that our understanding of basidiomycete biology has advanced significantly on many topics. Another important outcome has been that these large genome projects have brought the community together in consortia unprecedented before the genomic era.

These developments were the reason for us to suggest a special issue in FGB on Basidiomycete Genomics, to showcase some of the advances that have been made over the last two decades. The issue covers a range of topics, such as mating, plant pathogenicity and commercial cultivation of mushrooms, as well as a range of life styles, such as white and brown rot, and rusts. We would like to thank all authors for contributing their studies, and Nancy Keller and the staff at Elsevier for their support in preparing this issue.

\section{References}

Binder, M., Justo, A., et al., 2013. "Phylogenetic and phylogenomic overview of the Polyporales". Mycologia 105, 1350-1373.

Duplessis, S., Cuomo, C.A., et al, 2011. "Obligate biotrophy features unraveled by the genomic analysis of rust fungi". Proc Natl Acad Sci U S A 108, 9166-9171.

Eastwood, D.C., Floudas, D., et al, 2011. "The plant cell wall-decomposing machinery underlies the functional diversity of forest fungi". Science 333, 762-765. 
Floudas, D., Binder, M., et al, 2012. "The Paleozoic origin of enzymatic lignin decomposition reconstructed from 31 fungal genomes". Science 336, 1715-1719.

Kämper, J., Kahmann, R., et al, 2006. "Insights from the genome of the biotrophic fungal plant pathogen Ustilago maydis". Nature 444, 97-101.

Kohler, A., Kuo, A., et al, 2015. "Convergent losses of decay mechanisms and rapid turnover of symbiosis genes in mycorrhizal mutualists". Nat Genet 47, 410-415.

Martinez, D., Larrondo, L.F., et al, 2004. “Genome sequence of the lignocellulose degrading fungus Phanerochaete chrysosporium strain RP78". Nature Biotechnol 22, 695-700.

Morin, E., Kohler, A., et al, 2012. "Genome sequence of the button mushroom Agaricus bisporus reveals mechanisms governing adaptation to a humic-rich ecological niche". Proc Natl Acad Sci U S A 109, 17501-17506.

Ohm, R.A., de Jong, J.F., et al, 2010. "Genome sequence of the model mushroom Schizophyllum commune". Nature Biotechnol 28, 957-963.

Ronald P. de Vries, Miia R. Mäkelä, Kristiina S. Hildén, Jörg Kämper 